\title{
An exploratory study of some pediatric liver function parameters in a segment of North Indian children
}

\author{
(D) Abhaya Indrayan', (1) Mohini Bhargava2, (i) Shubham Shukla' \\ ${ }^{1}$ Clinical Research, Max Healthcare, Vaishali, Ghaziabad, India \\ ${ }^{2}$ Laboratory Services, Max Healthcare, Vaishali, Ghaziabad, India
}

\begin{abstract}
Objectives: Western clinical reference levels may not be valid for children in India because of differences in genetic profile, physique, dietary intake, lifestyle, and environmental factors; however, appropriate values for most biochemical parameters for children in India remain unknown. This study is an analysis of the total protein, albumin, globulin, albumin-globulin ratio, alanine aminotransferase, aspartate aminotransferase, gamma-glutamyl transferase, and alkaline phosphatase (ALP) levels in the serum of a segment of apparently healthy Indian children of aged 0-14 years.

Methods: Liver function data from tests conducted between January and June of 2019 for 371 children were extracted from the laboratory records of a tertiary care hospital and double-filtered to obtain uncontaminated values. The data were statistically tested for significance by age group and sex. Reference ranges of $2.5^{\text {th }}$ and $97.5^{\text {th }}$ percentiles were determined for age groups of 1-4, 5-9, and 10-14 years. Due to the limitation of the sample size, we did not provide a reference range for children aged less than 1 year.

Results: A significant sex difference $(p<0.001)$ was observed only for the ALP level. Age group differences were not significant (all $p>0.05$ ); however, reference ranges were provided for age groups within 1-14 years to provide specificity and assist with comparisons. The liver function values in the study group of Indian children differed from what have been reported for Western children.

Conclusion: The findings are suggestive and not confirmatory, as our sample was insufficient for a determination of definitive values. Nonetheless, the results provide valuable information and indicate a need to carry out more studies to delineate liver function parameters in Indian children since the values may differ from those of other populations.

Keywords: Children, enzymes, liver function, proteins, reference range
\end{abstract}

A dult medical parameters are rarely applicable to children, due to the smaller body and organ size, typical nutritional requirements, and the process of physiological development. A review of the literature indicated that the biochemical values of Indian children are generally not known. The marked difference in genetic profile, physique, dietary intake, lifestyle, and environmental factors suggests that the values in Indian subjects are likely different from those reported for Western subjects [1]. The preceding statement referred to adults, but applies equally well to children. The results of several studies indicate that some reference values reported for children in different populations reveal wide variation across countries, even when limited to Western countries.

The scope of this study was restricted to some liver function parameters. They reflect different phases of physiological development in children [2] and are used for the diagnosis of conditions such as liver injury, hepatitis, parasitic infection, and Wilson's disease [3], as well as hepatic steatosis [4], including non-alcoholic fatty liver disease. The aim of the present study was to examine the level of various proteins and enzymes in the serum of a segment of apparently healthy children in North India. The objective was to examine how age

Address for correspondence: Abhaya Indrayan, MD. Clinical Research, Max Healthcare, Vaishali, Ghaziabad, India

Phone: 9810315030 E-mail: a.indrayan@gmail.com ORCID: 0000-0002-5940-9666

Submitted Date: December 07, 2020 Accepted Date: January 19, 2021 Available Online Date: March 17, 2021

${ }^{\circ}$ Copyright 2021 by International Journal of Medical Biochemistry - Available online at www.internationalbiochemistry.com

OPEN ACCESS This work is licensed under a Creative Commons Attribution-NonCommercial 4.0 International License. 
and sex might affect these values in this population of children, whether they are different from those of adults, and whether the values in Indian children differ from counterparts in other countries. Since the liver chemistry of children varies with age and sex and requires customized reference ranges [5], estimates of reference ranges for different groups based on age and sex were provided, though we realize that the current sample is not sufficient in size or a random representative sample of healthy North Indian children. Thus, the reference ranges presented are suggestive and not confirmatory. The authors wish to be fully transparent, as is required for truthful and useful research [6].

In India, children in the general population rarely undergo liver function tests. In addition, ethical considerations restrict researchers from collecting samples from healthy children [7]. The present study used a relatively small sample, and therefore it is merely an exploratory study to generate a hypothesis and to initiate and promote potentially promising directions of further research [8]. It is insufficient to reach any firm conclusion. Since a large-scale study on a nationally representative sample of children is not envisioned in the near future in India, the results of this study could be a unit for a meta-analysis of many such studies conducted in the course of time. Such a meta-analysis can help to reach a firm conclusion regarding liver function parameter values in Indian children.

The liver function tests analyzed were serum levels of total protein, albumin, globulin, albumin-globulin (A/G) ratio, alanine aminotransferase (ALT or SGPT), aspartate aminotransferase (AST or SGOT), gamma-glutamyl transferase (GGT), and alkaline phosphatase (ALP). While the other parameters have well-known uses in the medical evaluation of patients, questions are sometimes raised about the utility of globulin levels and the $A / G$ ratio. Both of these values are calculated and not directly obtained. The globulin levels and the $A / G$ ratio are not as useful as the albumin and enzyme levels, but they provide helpful information when interpreted with levels of total protein. A high globulin level is used to detect paraproteins and low values indicate antibody deficiency [9]. A reduced A/G ratio can indicate inflammation [10].

\section{Materials and Methods}

The results of liver function tests performed between January 2019 and June 2019 were retrieved from the laboratory records of a large tertiary care hospital in Delhi-National Capital Region, India. Hospital patients are not an optimal study group, but efforts were made to select values that would ensure the validity of our results. Several studies have used similar hospital data [11-13].

The hospital is a private sector institution and the clientele is generally the more prosperous members of the local community. The hospital is also a member of a group used by several companies to provide preventive health checkups and care for their employees and their families. The test results gener- ally belong to these relatively healthy segments of the population and are appropriate for studying healthy values.

The extracted data set included the liver function test results of more than 18000 individuals. The findings for adults were reported separately [14]. Among these 18000, only 371 were children aged 0-14 years and the present study is based on those test results. Nearly one-third (34.8\%) of these patients were female.

The double filtration method [15] was used to assure that uncontaminated, healthy values were analyzed. The technique excludes the values of repeat investigations in the first filtration, and outliers and abnormal values based on box plots are eliminated in the second filtration. The children may have been ill at the time of blood sampling, and were excluded. The second filtration yielded a different number of subjects for various parameters. Many other authors have also excluded abnormal values to determine reference ranges, although different method have been employed for exclusion. For example, Bussler [16] excluded values of more than 3 SD outside the mean for subjects in Germany, and Ridefelt [17] excluded high ALP values to obtain reference values for children in Sweden.

The liver undergoes dramatic changes in structure and function during a child's development [18]; therefore, it is important to use suitable, homogeneous, age intervals. However, there is presently no consensus regarding proper age intervals to reflect the different phases of physiological development [7]. Authors have used different age intervals for different parameters. Li et al. [2] used groups of 2-10 and 11-14 years for albumin level but 2-3, 4-9, 10-12, and 13-14 years for ALP level. In contrast, Gupta [19] reported an albumin level for 1-7 and $>7$ years, and an ALP level for 2-10 years and adolescents. The Harriet Lane Handbook [20] used age groups of 1-3, 4-6, 7-9, and 10-11 years for ALT level, and 1-2 and 3-16 years for the albumin level. Li et al. [2] used a statistical method to determine homogeneous age-intervals, but the graphs provided in their report do not indicate any significant change in the values according to age intervals. Ridefelt et al. [21] used "qualified guessing" to partition by age and sex. In the absence of a consensus, conventional age intervals, namely, 0-1, 1-4, 5-9 and 10-14 years were used in this study for all of the parameters. This may be more practical, since these are used for many physiological parameters in children.

The age-sex distribution of the initial sample of children is presented in Table 1. The final sample used after double filtration is described in the Results section to avoid duplication.

All of the samples were analyzed on a Cobas 501 autoanalyzer (Roche Diagnostics, Basel, Switzerland) and the standard analytical method was uniformly followed in the laboratory during the entire period of the study to measure levels of the 8 liver function parameters analyzed. Strict internal and external quality control measures were adopted for accurate measurements. Details are provided in our earlier report, which examined adults [14]. 
Table 1. Age-sex distribution of the initial sample of children

\begin{tabular}{llll}
\hline Age group (years) & Male $\mathbf{n}(\%)$ & Female $\mathbf{n}(\%)$ & Total $\mathbf{n}(\%)$ \\
\hline$<1$ & $38(15.7)$ & $17(13.2)$ & $55(14.8)$ \\
$1-4$ & $45(18.6)$ & $35(27.1)$ & $80(21.6)$ \\
$5-9$ & $73(30.2)$ & $34(33.3)$ & $116(31.3)$ \\
$10-14$ & $86(35.5)$ & $129(100)$ & $120(32.3)$ \\
Total & $242(100)$ & $371(100)$ \\
\hline
\end{tabular}

Student's t-test was used to evaluate the statistical significance of the difference between the mean in male and female children, but a stricter criterion of $p<0.01$ ( $1 \%$ level of significance) was applied since there were multiple $p$ values [22]. The age difference in the means was tested using one-way analysis of variance (ANOVA) followed by the Tukey test, also at $1 \%$ level of significance.

In place of mean \pm 2 SD [23], the reference range was presented as $2.5^{\text {th }}$ to 97.5 th percentiles, which work equally well for both Gaussian and non-Gaussian distributions. This range is also recommended by the Clinical and Laboratory Standard Institute [24]. All of the calculations were performed using IBM
SPSS Statistics for Windows, Version 21.0 software (IBM Corp., Armonk, NY, USA).

Ethics approval for this study was granted by the Institutional Ethics Committee of Max Super Specialty Hospital, Vaishali (no: RS/MSSH/VSH/CRL/IEC/PATH/19-19).

\section{Results}

The sociodemographic data and the mean and SD of values of different parameters remaining after double filtration are shown in Table $2 a$ and $2 b$ by age group and sex. The $p$ values in the last column of these tables show that the evidence

Table 2a. Mean and SD of total protein, albumin, globulin, and albumin/globulin ratio in children by age and sex

\begin{tabular}{|c|c|c|c|c|c|c|c|c|}
\hline \multirow[t]{3}{*}{ Parameter } & \multirow{3}{*}{$\begin{array}{l}\text { Age group } \\
\text { (years) }\end{array}$} & \multicolumn{4}{|c|}{ Sex } & & & \multirow{3}{*}{$\begin{array}{l}\text { P value } \\
\text { for sex } \\
\text { difference }\end{array}$} \\
\hline & & \multicolumn{2}{|c|}{ Male } & \multicolumn{2}{|c|}{ Female } & \multicolumn{2}{|c|}{ Total $(\mathbf{M}+\mathbf{F})$} & \\
\hline & & $n^{*}$ & Mean (SD) & $n^{*}$ & Mean (SD) & $n^{*}$ & Mean (SD) & \\
\hline \multirow[t]{5}{*}{ Total protein (g/dL) } & $<1$ & 22 & $5.65(1.25)$ & 15 & $5.91(0.83)$ & 37 & $5.75(1.09)$ & 0.485 \\
\hline & $1-4$ & 37 & $6.86(0.61)$ & 31 & $7.12(0.49)$ & 68 & $6.98(0.57)$ & 0.060 \\
\hline & $5-9$ & 48 & $7.20(0.63)$ & 27 & $7.14(0.58)$ & 75 & $7.18(0.61)$ & 0.685 \\
\hline & $10-14$ & 57 & $7.14(0.71)$ & 29 & $7.22(0.67)$ & 86 & $7.17(0.69)$ & 0.616 \\
\hline & Combined (0-14) & 164 & $6.90(0.91)$ & 102 & $6.98(0.76)$ & 266 & $6.93(0.86)$ & 0.459 \\
\hline$P$ value for age difference & & & $<0.001$ & & $<0.001$ & & $<0.001$ & \\
\hline \multirow[t]{5}{*}{ Albumin (g/dL) } & $<1$ & 22 & $3.79(0.76)$ & 14 & $4.10(0.34)$ & 36 & $3.91(0.65)$ & 0.161 \\
\hline & $1-4$ & 37 & $4.27(0.52)$ & 28 & $4.66(0.25)$ & 65 & $4.44(0.46)$ & $<0.001$ \\
\hline & $5-9$ & 50 & $4.27(0.57)$ & 28 & $4.21(0.60)$ & 78 & $4.25(0.58)$ & 0.663 \\
\hline & $10-14$ & 58 & $4.38(0.54)$ & 27 & $4.32(0.53)$ & 85 & $4.36(0.54)$ & 0.633 \\
\hline & Combined (0-14) & 167 & $4.24(0.60)$ & 97 & $4.36(0.50)$ & 264 & $4.28(0.57)$ & 0.098 \\
\hline$P$ value for age difference & & & $<0.001$ & & $<0.001$ & & $<0.001$ & \\
\hline \multirow[t]{5}{*}{ Globulin (g/dL) } & $<1$ & 22 & $1.86(0.82)$ & 16 & $1.87(0.65)$ & 38 & $1.86(0.75)$ & 0.968 \\
\hline & $1-4$ & 39 & $2.59(0.49)$ & 34 & $2.54(0.44)$ & 73 & $2.57(0.47)$ & 0.650 \\
\hline & $5-9$ & 50 & $2.80(0.48)$ & 29 & $2.88(0.54)$ & 79 & $2.83(0.50)$ & 0.497 \\
\hline & $10-14$ & 58 & $2.73(0.46)$ & 29 & $3.00(0.40)$ & 87 & $2.82(0.45)$ & 0.009 \\
\hline & Combined (0-14) & 169 & $2.61(0.61)$ & 108 & $2.65(0.62)$ & 277 & $2.63(0.61)$ & 0.597 \\
\hline$P$ value for age difference & & & $<0.001$ & & $<0.001$ & & $<0.001$ & \\
\hline \multirow[t]{5}{*}{ A/G ratio } & $<1$ & 21 & $2.21(0.77)$ & 16 & $2.27(0.73)$ & 37 & $2.23(0.74)$ & 0.812 \\
\hline & $1-4$ & 39 & $1.67(0.43)$ & 35 & $1.73(0.49)$ & 74 & $1.70(0.46)$ & 0.577 \\
\hline & $5-9$ & 50 & $1.52(0.31)$ & 29 & $1.50(0.40)$ & 79 & $1.51(0.34)$ & 0.805 \\
\hline & $10-14$ & 58 & $1.64(0.32)$ & 29 & $1.44(0.32)$ & 87 & $1.57(0.33)$ & 0.007 \\
\hline & Combined (0-14) & 168 & $1.68(0.47)$ & 109 & $1.67(0.54)$ & 277 & $1.68(0.50)$ & 0.871 \\
\hline$P$ value for age difference & & \multicolumn{2}{|c|}{$<0.001$} & \multicolumn{2}{|c|}{$<0.001$} & \multicolumn{2}{|c|}{$<0.001$} & \\
\hline
\end{tabular}

*After double filtration. A/G: Albumin/globulin; F: Female; M: Male. 
Table $2 \mathrm{~b}$. Mean and SD of ALT, AST, GGT, and ALP in children by age group and sex

\begin{tabular}{|c|c|c|c|c|c|c|c|c|}
\hline \multirow[t]{2}{*}{ Parameter } & \multirow{2}{*}{$\begin{array}{l}\text { Age group } \\
\text { (years) }\end{array}$} & \multicolumn{4}{|c|}{ Sex } & & & \multirow{2}{*}{$\begin{array}{l}P \text { value } \\
\text { for sex } \\
\text { difference }\end{array}$} \\
\hline & & $n^{*}$ & Mean (SD) & $n^{*}$ & Mean (SD) & $n^{*}$ & Mean (SD) & \\
\hline \multirow[t]{4}{*}{$\mathrm{ALT}(\mathrm{U} / \mathrm{L})$} & $<1$ & 19 & $21.74(9.73)$ & 14 & $17.18(6.73)$ & 33 & $19.80(8.77)$ & 0.142 \\
\hline & $1-4$ & 31 & $18.87(8.57)$ & 34 & $18.69(9.79)$ & 65 & $18.77(9.16)$ & 0.938 \\
\hline & $5-9$ & 42 & $20.12(11.87)$ & 25 & $21.56(9.90)$ & 67 & $20.66(11.12)$ & 0.612 \\
\hline & Combined (0-14) & 141 & $20.93(10.87)$ & 97 & $19.17(8.78)$ & 238 & 20.21 (10.09) & 0.187 \\
\hline$P$ value for age difference & & & 0.456 & & 0.427 & & 0.513 & \\
\hline \multirow[t]{3}{*}{ AST (U/L) } & $<1$ & 19 & $37.91(13.80)$ & 12 & $27.58(8.60)$ & 31 & 33.91 (12.95) & 0.016 \\
\hline & $1-4$ & 33 & $37.71(12.02)$ & 35 & $34.97(11.85)$ & 68 & $36.30(11.92)$ & 0.347 \\
\hline & $5-9$ & 43 & $31.40(11.92)$ & 22 & $31.80(6.47)$ & 65 & $31.54(10.34)$ & 0.884 \\
\hline & $1-4$ & 34 & $13.56(4.51)$ & 32 & $11.25(2.86)$ & 66 & $12.44(3.95)$ & 0.016 \\
\hline & $5-9$ & 40 & $14.86(4.06)$ & 21 & $15.81(5.83)$ & 61 & $15.19(4.72)$ & 0.488 \\
\hline & $10-14$ & 42 & $15.11(4.32)$ & 24 & $17.71(6.71)$ & 66 & $16.05(5.41)$ & 0.060 \\
\hline & Combined (0-14) & 136 & $23.66(34.91)^{* *}$ & 91 & $22.39(31.59)^{* *}$ & 227 & $23.15(33.55)^{* *}$ & 0.781 \\
\hline$P$ value for age difference & & & $<0.001$ & & $<0.001$ & & $<0.001$ & \\
\hline \multirow[t]{5}{*}{$\operatorname{ALP}(\mathrm{U} / \mathrm{L})$} & $<1$ & 21 & $279.9(135.4)$ & 15 & $233.5(85.3)$ & 36 & $260.6(117.9)$ & 0.251 \\
\hline & $1-4$ & 36 & $210.39(62.16)$ & 34 & $190.68(58.82)$ & 70 & $200.8(60.9)$ & 0.178 \\
\hline & $5-9$ & 43 & $198.04(45.32)$ & 28 & $219.50(78.30)$ & 71 & $206.5(60.9)$ & 0.148 \\
\hline & $10-14$ & 57 & $272.40(85.17)$ & 26 & $151.88(50.67)$ & 83 & $234.6(94.3)$ & $<0.001$ \\
\hline & Combined (0-14) & 157 & $238.82(87.51)$ & 103 & $194.96(72.33)$ & 260 & $221.4(84.5)$ & $<0.001$ \\
\hline
\end{tabular}

*After double filtration. * ${ }^{*} \mathrm{SD}$ is high because of extremely high variation in infants. ALP: Alkaline phosphatase; ALT: Alanine aminotransferase; AST: Aspartate aminotransferase; F: Female; GGT: Gamma-glutamyl transferase; M: Male.

for sex difference was not sufficient for any parameter at a $1 \%$ level of significance, with the exception of albumin in the age group of 1-4 years, and globulin, A/G ratio, and ALP in the age group of 10-14 years. All other $p$ values for sex difference were $>0.01$. While a sex difference in the 10-14 group may be due to the differential effects of puberty, the male-female difference in the 1-4 group may be a random error in this study, as it did not persist in other age groups. When all of the age groups were considered together, the $p$ values for age differences were significant $(p<0.01)$ for all the parameters in both sexes according to an ANOVA F-test, but the Tukey test pair-wise comparisons at a $1 \%$ significance level revealed the following:

(i) On average, the protein levels (total protein, albumin, globulin, and $A / G$ ratio) were significantly different (lower total protein, albumin, and globulin, but higher $A / G$ ratio) in infants, but were not different in the 1-4, 5-9, and 10-14 groups. Thus, a single reference interval may be sufficient for all patients aged 1 to 14 years, but a reference range for each of these age groups was provided for comprehensiveness. The 0-1 group was not defined, as the reliability is not adequate for this age group. (ii) Among the enzymes, GGT and ALP also exhibited a difference in the mean level in infants in comparison with the other age groups, but no difference was observed between the 1-4, 5-9, and 10-14 groups. The GGT level was considerably higher in infants, and the ALP level was also slightly but significantly higher in infants.

(iii) The mean ALT level was not significantly different in any pairing of age groups. Thus, the same reference range can be used for children aged 0-14 years.

(iv) The AST level was higher on average in the 1-4 age group than in the other age groups, which could be the result of a random error. Thus, the same reference range can be used for all age groups 1-14 years.

The group aged less than 1 year had a large and clinically relevant difference (more than 10\%) when compared with the older age groups for most of these parameters. Protein levels, particularly globulin, were lower in both males and females (Table 2a), and GGT levels were considerably higher (more than 4 times) in infants than the older groups (Table $2 b$ ). This infant group requires a separate study with an adequately sized sample. Due 
to the small sample size in this study, it would be inappropriate to split this age group further into neonates and post-neonates due to potential differences. There are reports in the literature of different values for some of these parameters in young children (see The Harriet Lane Handbook [20] and Gupta [19] for GGTP level and AST level, and Tietz [25] for total protein level). Due to the limitation of the sample size, we did not provide a reference range for children aged less than 1 year.

The reference ranges are provided in Table 3 as $2.5^{\text {th }}-97.5^{\text {th }}$ percentile values. The age group of 0-1 was excluded as a result of the small number of children in that group and the consequent poor reliability of reference ranges. The reference ranges were presented without gender differentiation since the difference in means was not statistically significant, with the exception of a lower ALP level in females aged 10-14 years. Ranges were provided for different age groups despite a non-significant difference for comparability with the literature and use in additional studies.

\begin{tabular}{|c|c|c|c|}
\hline & $\begin{array}{l}\text { Age } \\
\text { (years) }\end{array}$ & Sex & $\begin{array}{l}\text { Reference } \\
\text { range }\end{array}$ \\
\hline \multirow[t]{3}{*}{ Total protein (g/dL) } & $1-4$ & $M$ or $F$ & $5.5-8.0$ \\
\hline & $5-9$ & & $5.0-8.4$ \\
\hline & $10-14$ & & $5.7-8.4$ \\
\hline \multirow[t]{3}{*}{ Albumin (g/dL) } & $1-4$ & $M$ or $F$ & $3.2-5.1$ \\
\hline & $5-9$ & & $3.2-5.1$ \\
\hline & $10-14$ & & $3.1-5.2$ \\
\hline \multirow[t]{3}{*}{ Globulin (g/dL) } & $1-4$ & Mor $F$ & $1.8-3.6$ \\
\hline & $5-9$ & & $1.9-4.0$ \\
\hline & $10-14$ & & $2.0-3.8$ \\
\hline \multirow[t]{3}{*}{ A/G ratio } & $1-4$ & M or F & $0.65-2.45$ \\
\hline & $5-9$ & & $0.68-2.08$ \\
\hline & $10-14$ & & $0.90-2.18$ \\
\hline \multirow[t]{3}{*}{ ALT (U/L) } & $1-4$ & $M$ or $F$ & $3.9-41.4$ \\
\hline & $5-9$ & & $5.6-47.8$ \\
\hline & $10-14$ & & $8.5-49.3$ \\
\hline \multirow[t]{3}{*}{ AST (U/L) } & $1-4$ & $M$ or $F$ & $15.9-64.1$ \\
\hline & $5-9$ & & $11.8-64.8$ \\
\hline & $10-14$ & & $15.4-62.5$ \\
\hline \multirow[t]{4}{*}{ GGT (U/L) } & $1-4$ & M or $F$ & \\
\hline & $6.7-25.6$ & & \\
\hline & $5-9$ & & $7.6-29.1$ \\
\hline & $10-14$ & & 7.7-31.6 \\
\hline \multirow[t]{4}{*}{$\mathrm{ALP}(\mathrm{U} / \mathrm{L})$} & $1-4$ & $M$ or $F$ & $81-335$ \\
\hline & $5-9$ & & $96-367$ \\
\hline & $10-14$ & M & $96-444$ \\
\hline & & $\mathrm{F}$ & $77-263$ \\
\hline
\end{tabular}

A/G: Albumin-globulin ratio; ALP: Alkaline phosphatase; ALT: Alanine aminotransferase; AST: Aspartate aminotransferase; F: Female; GGT: Gammaglutamyl transferase; M: Male.
The trend of the median and $2.5^{\text {th }}$ and $97.5^{\text {th }}$ percentiles of all 8 parameters in male and female children by age group are shown in Figures $1 \mathrm{a}$ and $1 \mathrm{~b}$. The age group of 0-1 year was also included to illustrate the difference between values in infants and the other age groups. The figures show that, in general, there was a small increasing trend in the values of total protein, albumin, and particularly globulin in both sexes and a decreasing $A / G$ ratio as age increased from 1-14 years although, as mentioned earlier, the difference across age groups was not statistically significant. Enzymes levels (ALT, AST, GGT and ALP) did not demonstrate any discernible trend from 1-14 years.

\section{Discussion}

A literature review did not reveal any study of pediatric values of liver function parameters in India. Studies from around the world include the CALIPER (Canadian Laboratory Initiative on Pediatric Reference Intervals) project [26], the Ridefelt study [27] of data from Sweden, Clifford's research in the USA [28], and Lai et al. in Taiwan [29]. These studies provide various values and none can be considered accurate for Indian children.

Age differentials: Li et al. [2] reported increasing values of total protein and albumin level in Han children (China) as age increased from 2-14 years. Ridefelt et al. [20] also reported a slight increase in albumin level in children of Denmark and Sweden (they did not report total protein level). In contrast, our results with a Tukey test suggested that protein levels (total protein, albumin, and globulin) did not significantly differ between the age groups of 1-4, 5-9, and 10-14 years, but the levels were significantly lower in children younger than 1 year of age. The levels stabilized after the age of 1 year, as also reported by Andropoulos [30] for children in Western countries.

For enzyme levels, Ridefelt et al. [21] reported high ALP and AST levels in infants that dropped after the age of 1 year. The trend in ALP level after 1 year of age is erratic in their report, with unexplained escalations and declines in different pediatric age groups. For AST, they provided a reference range for the age groups of 2-8 and 9-17 years, implying that there are no significant differences within those age-intervals. Li et al. [2] reported a decreasing level of AST as age increased 2-14 years, with increasing GGT values. They also reported an erratic trend in ALP and ALT levels over different pediatric age groups.

We observed steeply high levels of GGT in infants (more than 4 times) and slightly but significantly higher ALP levels in this age group (Table $2 \mathrm{~b}$ ). The results of a Tukey test indicated that the levels of these parameters appeared to stabilize after the age of 1 year, as there were no significant differences in the mean levels in the 1-4, 5-9, or 10-14 groups. The mean ALT levels were not significantly different in any age group 0-14 years. The mean AST level was significantly higher in the 1-4 age group, but that would seem to be a random error because there is no known biological reason for this result in this particular age group and it did not persist in other age groups. 
Table 4a. Reference interval for total protein, albumin, and globulin reported in the literature and comparison with our values

\begin{tabular}{|c|c|c|c|c|c|c|c|c|c|c|c|c|c|c|c|c|}
\hline Parameter & Ref & Age & Sex & $\begin{array}{l}\text { Ref } \\
\text { range }\end{array}$ & Ref & Age & Sex & $\begin{array}{l}\text { Ref } \\
\text { range }\end{array}$ & Ref & Age & Sex & $\begin{array}{l}\text { Ref } \\
\text { range }\end{array}$ & Ref & Age & Sex & $\begin{array}{l}\text { Ref } \\
\text { range }\end{array}$ \\
\hline Total protein & Our & $1-4 y$ & $\mathrm{~F}+\mathrm{M}$ & $5.5-8.0$ & Harriet & $0-15 d$ & $\mathrm{~F}+\mathrm{M}$ & 4.4-7.6 & Gupta & Term & & & & & & \\
\hline \multirow[t]{5}{*}{$(g / d L)$} & study & $5-9 y$ & $\mathrm{~F}+\mathrm{M}$ & $5.0-8.4$ & Lane & $15 d-1 y$ & $\mathrm{~F}+\mathrm{M}$ & $5.1-7.3$ & & neonate & $\mathrm{F}+\mathrm{M}$ & $4.6-7.7$ & Burtis & Newborn & $\mathrm{F}+\mathrm{M}$ & $4.6-7.0$ \\
\hline & & $10-14 y$ & $\mathrm{~F}+\mathrm{M}$ & $5.7-8.4$ & Handbook & $1-2 y$ & $\mathrm{~F}+\mathrm{M}$ & $5.6-7.5$ & & $1-7 y$ & $\mathrm{~F}+\mathrm{M}$ & $6.1-7.9$ & and & $1 w$ & $\mathrm{~F}+\mathrm{M}$ & 4.4-7.6 \\
\hline & & & & & & $3-16 y$ & $\mathrm{~F}+\mathrm{M}$ & $6.0-8.0$ & & $>7 y$ & $\mathrm{~F}+\mathrm{M}$ & $6.4-8.2$ & Bruns & $7 m-1 y$ & $\mathrm{~F}+\mathrm{M}$ & $5.1-7.3$ \\
\hline & & & & & & & & & & & & & & $1-2 y$ & $\mathrm{~F}+\mathrm{M}$ & $5.6-7.5$ \\
\hline & & & & & & & & & & & & & & $>2 y$ & $\mathrm{~F}+\mathrm{M}$ & $6.0-8.0$ \\
\hline Albumin & & $1-4 y$ & $\mathrm{~F}+\mathrm{M}$ & $3.2-5.1$ & & $0-15 d$ & $\mathrm{~F}+\mathrm{M}$ & $3.0-3.9$ & & Term & & & & & & \\
\hline \multirow[t]{3}{*}{$(g / d L)$} & & $5-9 y$ & $\mathrm{~F}+\mathrm{M}$ & $3.2-5.1$ & & $15 d-1 y$ & $\mathrm{~F}+\mathrm{M}$ & $2.2-4.8$ & & neonate & $\mathrm{F}+\mathrm{M}$ & $2.5-5.0$ & & $0-4 d$ & $\mathrm{~F}+\mathrm{M}$ & $2.8-4.4$ \\
\hline & & $10-14 y$ & $\mathrm{~F}+\mathrm{M}$ & $3.1-5.2$ & & $1-2 y$ & $\mathrm{~F}+\mathrm{M}$ & $3.6-5.2$ & & $1-7 y$ & $\mathrm{~F}+\mathrm{M}$ & $4.0-5.0$ & & $4 d-14 y$ & $\mathrm{~F}+\mathrm{M}$ & $3.8-5.4$ \\
\hline & & & & & & $3-16 y$ & $\mathrm{~F}+\mathrm{M}$ & $3.6-5.2$ & & $>7 y$ & $\mathrm{~F}+\mathrm{M}$ & $3.4-5.0$ & & & & \\
\hline
\end{tabular}

d: Days; m: Months; Ref: Reference; w: Weeks; y: Years.

Table 4b. Reference interval for ALT, AST, GGT, and ALP reported in the literature and comparison with our values

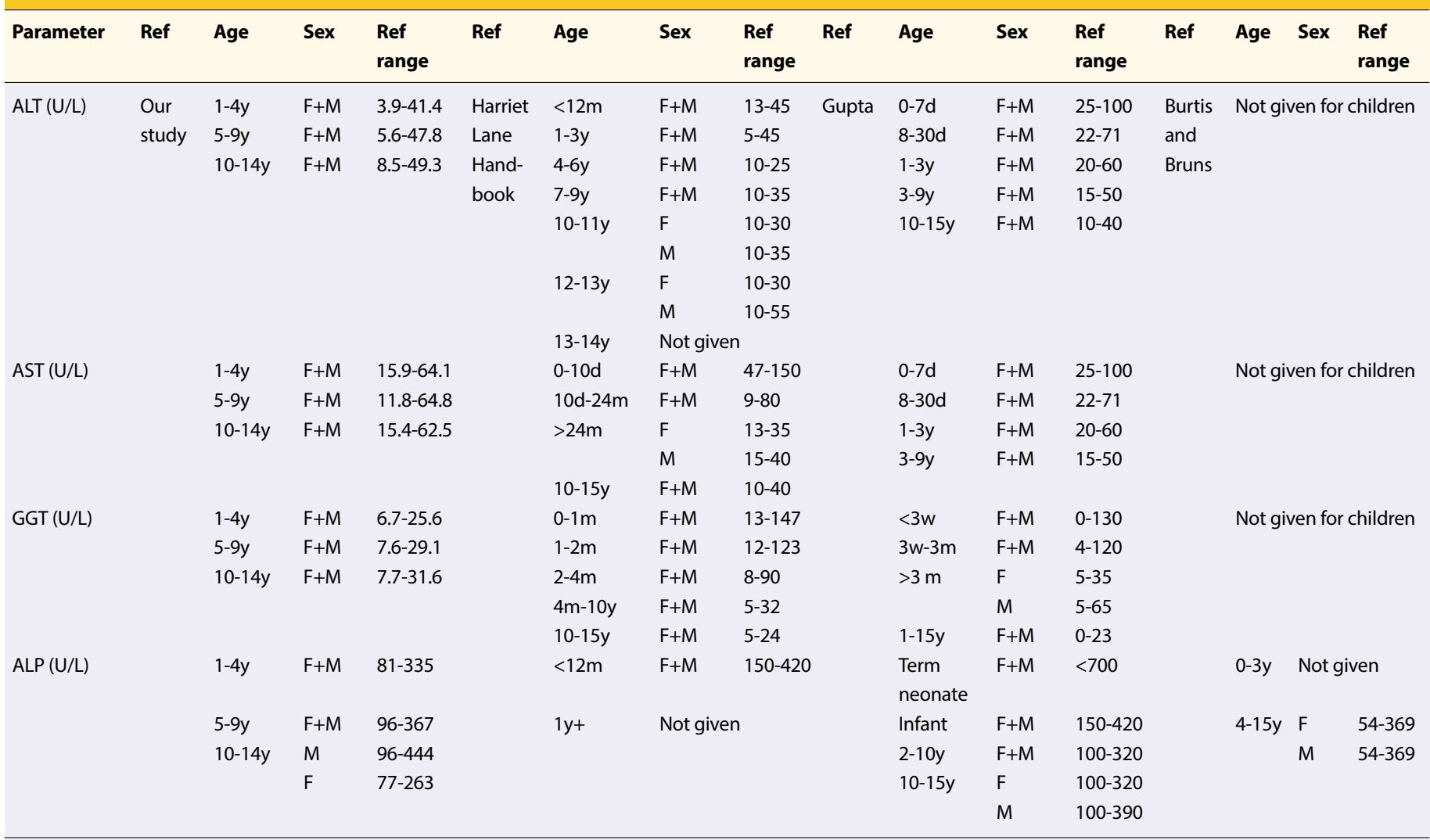

ALP: Alkaline phosphatase; ALT: Alanine aminotransferase; AST: Aspartate aminotransferase; d: Days; F: Female; GGT: Gamma-glutamyl transferase; M: Male; m: Months; Ref: Reference; w: Weeks; y: Years.

Sex differentials: There was no statistically significant difference between the male and female children in our study at the strict significance level of $1 \%$, with the exception of a lower mean ALP level in the females of the 10-14 age group (Table 2b). Ridefelt [21] reported a common reference range for albumin, ALT, ALP, and AST for male and female children up to age 14 in Denmark and Sweden, suggesting that there is no significant difference between the levels in male and female children in that population. The Harriet Lane Handbook [20] uses the same levels of ALT, ALP, AST, GGT, total protein, and albumin for male and female children. Thus, our finding of significantly different levels of ALP in boys and girls aged 10-14 years needs further investigation. Akirov [31] also observed different peak ALP levels in boys and girls of this age.

Comparison with other countries: Table $4 \mathrm{a}$ and $4 \mathrm{~b}$ provide the reference range reported by different authors and the values found in our study. Globulin and A/G ratio values were excluded from these tables, as not much information was available. 




Figure 1a. Age-sex trend of the median and reference range for the levels of total protein, albumin, globulin, and the albumin-globulin ratio in children.

A/G: Albumin-globulin. 


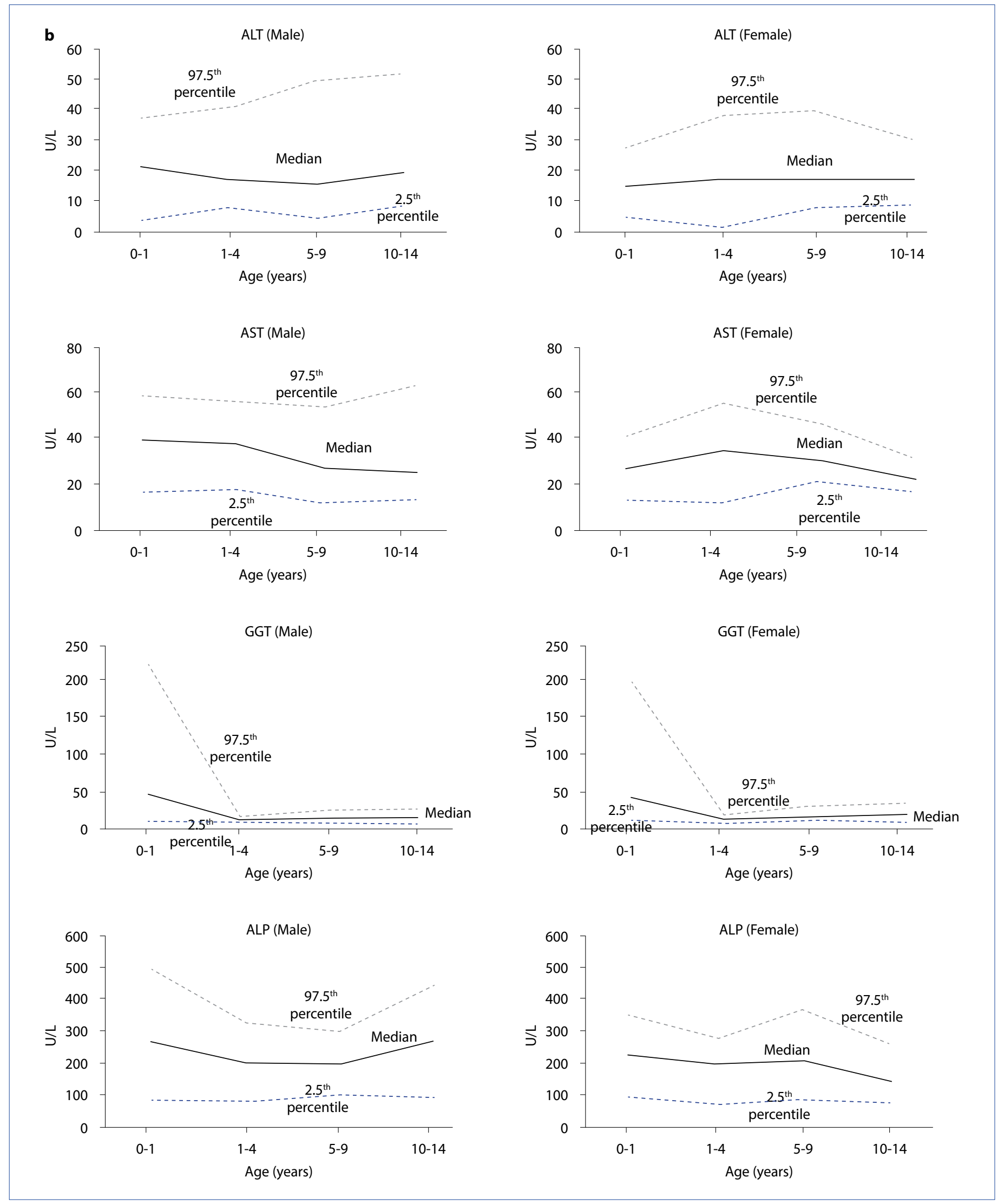

Figure 1b. Age-sex trend of the median and reference range for the levels of ALT, AST, GGT, and ALP in children.

ALP: Alkaline phosphatase; ALT: Alanine aminotransferase; AST: Aspartate aminotransferase; GGT: Gamma-glutamyl transferase. 
The wide variation across different reports suggests that values for children need to be studied with more precision, and that age and sex need to be clearly specified where differences exist. At present there is no clarity. The reference ranges obtained in our study are also different. Total protein and albumin levels were slightly lower in our study group than other children of corresponding age, but other parameters did not follow any consistent pattern and the values were different. More such studies are needed to establish precise reference ranges for Indian children.

Comparison of the levels in children with values previously reported for adults of the same population have revealed that generally, the levels of proteins (total protein, albumin, globulin, and $A / G$ ratio) were nearly the same in children aged 1-14 years as in adults, but there was some variation with regard to enzymes levels [14]. The AST and GGT levels were slightly lower, and the levels of AST and ALP were slightly higher in children than in adults. There is no comparable study for India, and there may also be regional differences. If this difference is substantiated, the biological reason should be investigated. The results for children in other countries are not uniform. We have cited some publications that are generally consulted for reference ranges. The Harriet Lane Handbook [24] reported lower values of total protein, albumin, and GGT in children aged 0-14 years compared with adults, but very similar ALT and AST levels. It also reports slightly higher levels of ALP in children than adults. Tietz [25] reported slightly lower values of total protein in children, but not in other parameters. Our results for a segment of Indian children are different and do not conform to any of the values previously reported. This could be a result of sampling error, but the previously published values also differ from one another. Such variations in the literature from different settings further underscores the need to carry out a large-scale study with a representative sample of children in India to resolve this issue.

\section{Conclusion}

To the best of our knowledge, this study is the first in the literature to investigate liver function parameters in Indian children. We analyzed the levels of total protein, albumin, globulin, A/G ratio, AST, ALT, ALP, and GGT in apparently healthy children aged 0-14 years. Though we used a sample of more than 300 , we are calling it an exploratory study since science requires modesty [32]. The study has generated interesting hypotheses for further investigation. First, the GGT level in infants was nearly 4 times the level in children 1-14 years of age. Second, there was no significant male-female difference in any of the 8 liver function parameters examined in this study, except the ALP level in the group aged 10-14 years. Third, the protein levels (total protein, albumin, globulin, and $A / G$ ratio) were nearly the same in children of 1-14 years as in adults, but the AST and GGT levels were slightly lower in children, and the AST and ALP levels were slightly higher. Lastly, we provide preliminary reference ranges for these parameters for Indian chil- dren aged 1-4, 5-9 and 10-14 years. These are different from previously reported values. Due to the limitation of a relatively small sample, our reference ranges are suggestive and not confirmatory. Further studies will confirm or deny our findings and add to the comprehensive knowledge.

Conflict of Interest: The authors declare no conflict of interest.

Ethics Committee Approval: This study was approved by the Institutional Ethics Committee of Max Super Specialty Hospital, Vaishali (no: RS/MSSH/VSH/CRL/IEC/PATH/19-19).

Financial Disclosure: We did not receive any funding from any source for this work.

Peer-review: Externally peer-reviewed.

Authorship Contributions: Concept - A.I.; Design - A.I. S.S.; Supervision - S.S.; Funding - M.B.; Materials - M.B.; Data collection \&/or processing - M.B., S.S.; Analysis and/or interpretation - A.I., M.B., S.S.; Literature search - S.S.; Writing - A.I., M.B.; Critical review - A.I., M.B., S.S.

\section{References}

1. Sairam S, Domalapalli S, Muthu S, Swaminathan J, Ramesh VA, Sekhar L, et al. Hematological and biochemical parameters in apparently healthy Indian population: defining reference intervals. Indian J Clin Biochem 2014;29(3):290-7. [CrossRef]

2. Li X, Wang D, Yang C, Zhou Q, Zhuoga SL, Wang LQ, et al. Establishment of age- and gender-specific pediatric reference intervals for liver function tests in healthy Han children. World J Pediatr 2018;14(2):151-9. [CrossRef]

3. D'Agata ID, Balistreri WF. Evaluation of liver disease in the pediatric patient. Pediatr Rev 1999;20(11):376-90. [CrossRef]

4. Draijer LG, Feddouli S, Bohte AE. Comparison of diagnostic accuracy of screening tests ALT and ultrasound for pediatric non-alcoholic fatty liver disease. Eur J Pediatr 2019;178:863-70.

5. Stirnadel-Farrant HA, Galwey N, Bains C, Yancey C, Hunt CM. Children's liver chemistries vary with age and sex and require customized pediatric reference ranges. Regul Toxicol Pharmacol 2015;73(1):349-55. [CrossRef]

6. Ioannidis JPA. How to make more published research true. PLoS Med 2014;11:e1001747. [CrossRef]

7. Ridefelt $P$, Hellberg $D$, Aldrimer $M$, Gustafsson J. Estimating reliable paediatric reference intervals in clinical chemistry and haematology. Acta Paediatr 2014;103(1):10-5. [CrossRef]

8. Schwab S, Held L. Different worlds: confirmatory versus exploratory research. Significance 2020;17(2):8-9. [CrossRef]

9. Jolles S, Borrell R, Zouwail S, Heaps A, Sharp H, Moody M, et al. Calculated globulin (CG) as a screening test for antibody deficiency. Clin Exp Immunol 2014;177(3):671-8. [CrossRef]

10. Walsh CJ, Cocilova C, Restivo J, Flewelling L, Milton S. Immune function in Trachemys scripta following exposure to a predominant brevetoxin congener, $\mathrm{PbTx}-3$, as a model for potential health impacts for sea turtles naturally exposed to brevetoxins. Ecotoxicology 2019;28(9):1085-104. [CrossRef] 
11. Shaw JL, Cohen A, Konforte D, Binesh-Marvasti T, Colantonio DA, Adeli K. Validity of establishing pediatric reference intervals based on hospital patient data: a comparison of the modified Hoffmann approach to CALIPER reference intervals obtained in healthy children. Clin Biochem 2014;47(3):16672. [CrossRef]

12. Cho SM, Lee SG, Kim HS, Kim JH. Establishing pediatric reference intervals for 13 biochemical analytes derived from normal subjects in a pediatric endocrinology clinic in Korea. Clin Biochem 2014;47(18):268-71. [CrossRef]

13. Loh TP, Antoniou G, Baghurst P, Metz MP. Development of paediatric biochemistry centile charts as a complement to laboratory reference intervals. Pathology 2014;46(4):336-43. [CrossRef]

14. Indrayan A, Bhargawa M, Shukla S. Reference interval with age-gender variation for 4 liver function parameters in an adult segment of the Indian population. Int J Med Biochem 2020;3(2):82-90.

15. Indrayan A, Bhargawa M, Shukla S. Utilization of hospital laboratory data for establishing normal reference interval of quantitative medical parameter: Double filtration method. Indian J Med Biochem 2020;24(1):9-11. [CrossRef]

16. Bussler S, Vogel M, Pietzner D, Harms K, Buzek T, Penke M, et al. New pediatric percentiles of liver enzyme serum levels (alanine aminotransferase, aspartate aminotransferase, $\mathrm{y}$-glutamyltransferase): effects of age, sex, body mass index, and pubertal stage. Hepatology 2018;68(4):1319-30. [CrossRef]

17. Ridefelt $P$, Gustafsson J, Aldrimer M, Hellberg D. Alkaline phosphatase in healthy children: reference intervals and prevalence of elevated levels. Horm Res Paediatr 2014;82(6):399404. [CrossRef]

18. Piñeiro-Carrero VM, Piñeiro EO. Liver. Pediatrics 2004;113(4 Suppl):1097-106.

19. Gupta P. PG textbook of pediatrics. 2nd ed. New Delhi: Jaypee Brothers; 2017.

20. Arcara K, Tschudy M. The Harriet Lane handbook: a manual for pediatric house officers. 19th ed. Maryland Heights, Missouri: Mosby Elsevier; 2012.

21. Ridefelt $P$, Hilsted $L$, Juul A, Hellberg D, Rustad P. Pediatric reference intervals for general clinical chemistry components merging of studies from Denmark and Sweden. Scand J Clin Lab Invest 2018;78(5):365-72. [CrossRef]
22. Anderson SF. Misinterpreting $\mathrm{p}$ : The discrepancy between $\mathrm{p}$ values and the probability the null hypothesis is true, the influence of multiple testing, and implications for the replication crisis. Psychol Methods 2020;25(5):596-609. [CrossRef]

23. Walker BR, College NR, Ralston SH, Penman ID, Britton R. Davidson's principles and practice of medicine. 22nd ed. London: Churchill Livingstone-Elsevier; 2014. p. 5.

24. Clinical and Laboratory Standard Institute (CLSI). EP28-A3C. Defining, establishing, and verifying reference intervals in the clinical laboratory; approved guideline - third edition. Available at: https://clsi.org/media/1421/ep28a3c_sample.pdf. Accessed Mar 15, 2021.

25. Burtis CA, Bruns DE. Tietz fundamentals of clinical chemistry and medical diagnostics. 7th ed. Philadelphia: Elsevier; 2015.

26. Colantonio DA, Kyriakopoulou L, Chan MK, Daly CH, Brinc D, Venner AA, et al. Closing the gaps in pediatric laboratory reference intervals: a CALIPER database of 40 biochemical markers in a healthy and multiethnic population of children. Clin Chem 2012;58(5):854-68. [CrossRef]

27. Ridefelt P. Pediatric reference intervals - the Swedish experience. Clin Biochem 2014;47(9):740-1. [CrossRef]

28. Clifford SM, Bunker AM, Jacobsen JR, Roberts WL. Age and gender specific pediatric reference intervals for aldolase, amylase, ceruloplasmin, creatine kinase, pancreatic amylase, prealbumin, and uric acid. Clin Chim Acta 2011;412(9-10):78890. [CrossRef]

29. Lai DS, Chen SC, Chang YH, Chen CY, Lin JB, Lin YJ, et al. Pediatric reference intervals for several biochemical analytes in school children in Central Taiwan. J Formos Med Assoc 2009;108(12):957-63. [CrossRef]

30. Andropoulos DB. Appendix B: pediatric normal laboratory values. In: Gregory GA, Andropoulos DB, editors. Gregory's pediatric anesthesia. 5th ed. Hoboken, New Jersey: Blackwell Publishing; 2012. [CrossRef]

31. Akirov A. Liver enzymes in children, adolescents are affected by obesity. Endocrinol Advisor 2019. Available at: https:// www.endocrinologyadvisor.com/home/topics/pediatric-endocrinology/liver-enzymes-in-children-are-affected-by-overweight-and-obesity/. Accessed Aug 8, 2020.

32. Wasserstein RL, Schirm AL, Lazar NA. Moving to a world beyond "p<0.05." Am Stat 2019;73(Suppl. 1):1-19. [CrossRef] 